\section{Survey of use of herbal and home remedies for hair and scalp among women in North West Saudi Arabia}

\author{
Abdullah Alyoussef \\ Department of Internal Medicine \\ (Dermatology), Faculty of Medicine, \\ University of Tabuk, Saudi Arabia
}

\begin{abstract}
Herbal products and home remedies, especially those used as cosmetics, are widely used worldwide. Therefore, we conducted this study to discover the pattern of use of remedies in treating hair and scalp disorders in Tabuk, North West area of Saudi Arabia. A survey about use of herbal products and home remedies was prepared to evaluate their in hair and scalp. The questionnaire was distributed to 149 female hairdressers, hair products sellers and traditional healers as well as female customers in these places. We found about forty-one plants and eleven home remedies used for hair and scalp in Tabuk area. The most widely used plants were Henna (15.01\%), coconut $(10.22 \%)$ and olive $(8.14 \%)$. They were widely used in hair damage $(32.01 \%)$, hair endings $(21.95 \%)$ and hair loss $(21.94 \%)$. In parallel, the most widely used home remedies were yogurt (32.42\%), eggs $(26.91 \%)$ and honey (23.85\%). They were widely used in hair damage (45.57\%), hair endings $(26.91 \%)$ and hair loss (19.88\%). There were no differences between participants in the pattern of use of remedies regarding their education level of age group. In conclusion, many natural herbal medicine and home remedies are still in use in North West region of Saudi Arabia for hair and scalp. There is a great shortage in medical sources of information. Finally, many of used remedies lacks important scientific information about their usage and safety.
\end{abstract}

\section{Introduction}

Cosmetic products are defined as any substance or mixture that is prepared to be applied on the outer parts of human body aiming for cleaning, improving appearance, perfuming or to keep outer parts in a good condition. Hair is one of the most important human features. It produces many important functions in our body including protection, thermoregulation, sensation and secretion of sebum and pheromones. ${ }^{1}$ Hair follicles are considered a highly complex dynamic skin extension. Their structure includes both epithelial and mesenchymal tissues. They are engaged in hair production and received all required nutrients for growth from capillaries in follicle dermal papilla cells. $^{2}$

Different hair diseases and disorders are highly spread in adults. These disorders results in psychosocial problem leading to reduction in quality of life. ${ }^{3} \mathrm{Next}$, they push patients to search for available treatment in either medical providers or marketplace. Some of these disorders might start as simple as dandruff and hair ends split or might be proceed to severe problems as hair loss or alopecia regardless of the cause. Male hair loss generally starts in front and temporal region and can end up with complete baldness, while female hair loss takes place in the central are of scalp and will not end up with complete baldness. ${ }^{4}$ Alopecia can be divided into non scaring alopecia as alopecia areata, androgenic alopecia, telogen effluvium, traumatic alopecia, tinea capitis and androgen effluvium as well as scaring alopecia as tinea capitis, alopecia mucinosa and alopecia neoplastica. ${ }^{5}$ However, to simplify the survey for participants with no experience in types of hair loss, we only asked about hair loss.

One of the widely spread therapy method is using available herbal medicine and home remedies. Many people in both developing and developed countries still use medical and cosmetic products from natural sources. ${ }^{6}$ Studies have shown that being female, middle aged, employed, having a higher household income and more education are associated with increased alternative medicine use. ${ }^{7}$ Many people preferred herbal and home remedies for general health and wellbeing. Other people use remedies as supplementary to conventional medicine. The choice of remedies may reflect religious beliefs. Finally, individuals with more control on their health status are more likely to try remedies before seeking for a physician help. ${ }^{8}$ The use of herbal and home remedies differs from one place to another according to differences in cultures and availability of these materials. ${ }^{9}$ Therefore, we conducted this study in order to collect important information about the use of herbal medicine and home remedies in treating different hair and scalp disorders between female participants in North West Saudi Arabia.
Correspondence: Abdullah Alyoussef, Associate Professor of Dermatology \& Venerology (Hair AND Scalp Disorders), Faculty of Medicine, University of Tabuk, Tabuk, 71471, Saudi Arabia

Tel.: +966504629800

E-mail: aalyoussef@ut.edu.sa

Key words: Hair; herbal medicine; home remedies; North West Saudi Arabia; scalp.

Conflict of interest: the author declares no potential conflict of interests.

Received for publication: 4 June 2020.

Accepted for publication: 8 September 2020.

This work is licensed under a Creative Commons Attribution-NonCommercial 4.0 International License (CC BY-NC 4.0).

(Copyright: the Author(s), 2020

Licensee PAGEPress, Italy

Dermatology Reports 2020; 12:8651

doi:10.4081/dr.2020.8651

\section{Materials and Methods}

\section{Subjects}

We prepared a special survey for evaluation of herbal and home remedies products which are used as cosmetics or used for treating different hair and scalp disorders in the period between September and December 2019. The questionnaire was distributed in Tabuk area in North West Saudi Arabia. The study was conducting according to requirements of declaration of Helsinki. All participants signed an informed consent.

\section{Data collection}

The study was conducted using direct interview with female hairdresser, hair products sellers and traditional healers as well as female customers in these places for collecting information about their method of treating different types of hair and scalp disorders by herbal and home remedies as well as their use as cosmetics. The questionnaire is specially designed for the study. It was divided into three parts. The first part collected the socio-demographic characteristics of participants as well as data about their source of information for treating these disorders. The second part collected data about the use of herbal plants. The third part collected data about the use of home remedies. The questionnaire consists of a table with herbal or home remedies in the rows and the hair use in columns. The participant has to tick the remedy with its use. In addition, at the end of parts two and three, there is an open-ended question ask- 
ing the participants to describe any remedies they used previously and not listed in the survey. An Arabic version of the questionnaire was used.

\section{Data analysis}

Data analysis were done using Excel program (Microsoft Co, 2013). The number and percent of use for each plant, home remedy and disease were used to describe data.

\section{Results}

\section{Socio-demographic characteristics}

Out of 186 accepted to participate in and returned the survey, 37 surveys were incomplete and excluded. Therefore, the final number of participants is 149. The socio-demographic characteristics of the participants were summarized in Table 1. Although, the survey covers all age and education levels, majority of participants were in the age range of 19-26 years with university level education. All the sociodemographic characteristics were in accordance with Governmental records in Saudi Arabia. ${ }^{10}$

\section{Sources of information}

Retrieving participants' sources of information reveals that the major source of information is social media $(27.51 \%)$ followed by physicians and pharmacists $(26.85 \%)$, media (14.77\%), internet websites $(12.75 \%)$, family and friends $(11.41 \%)$, herbalists $(4.03 \%)$ and medical books $(2.68 \%)$. Therefore, the major sources of information were represented by social pathway as represented by media, social media, internet, family and friends (66.44\%) compared with formal pathway as represented by medical books and health practitioners $(29.53 \%)$.

According to Figure 1a, majority of young participants depends on social media $(37.63 \%)$ and physicians and pharmacists $(19.80 \%)$ for their knowledge. In intermediate age group, majority of participants depend on physicians and pharmacists $(45.45 \%)$ and media (27.27\%). The participants over 45 years depends mainly on physicians and pharmacists $(33.33 \%)$ and media $(25.67 \%)$. In addition, classification of participants according to education level showed that the major source for participants with university or high school levels is the social media, physicians and pharmacists. The major source for participants with primary and elementary school levels is media and for illiterates is the herbal shops (Figure 1b).

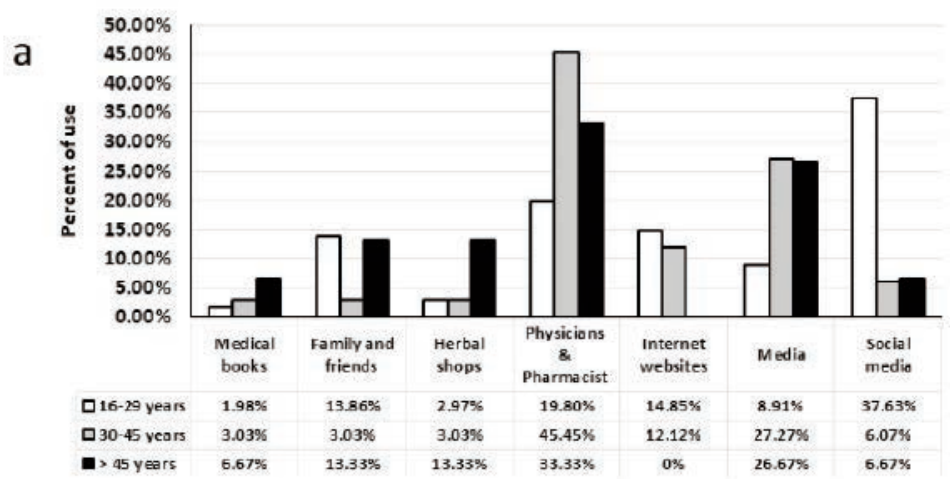

b

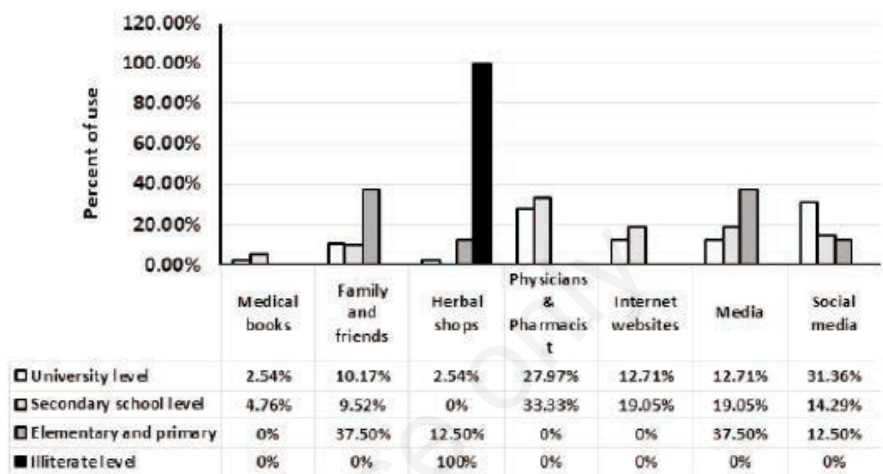

Figure 1. Sources of knowledge about herbal and home remedies of participants classified according to age (a) and according to education levels (b).
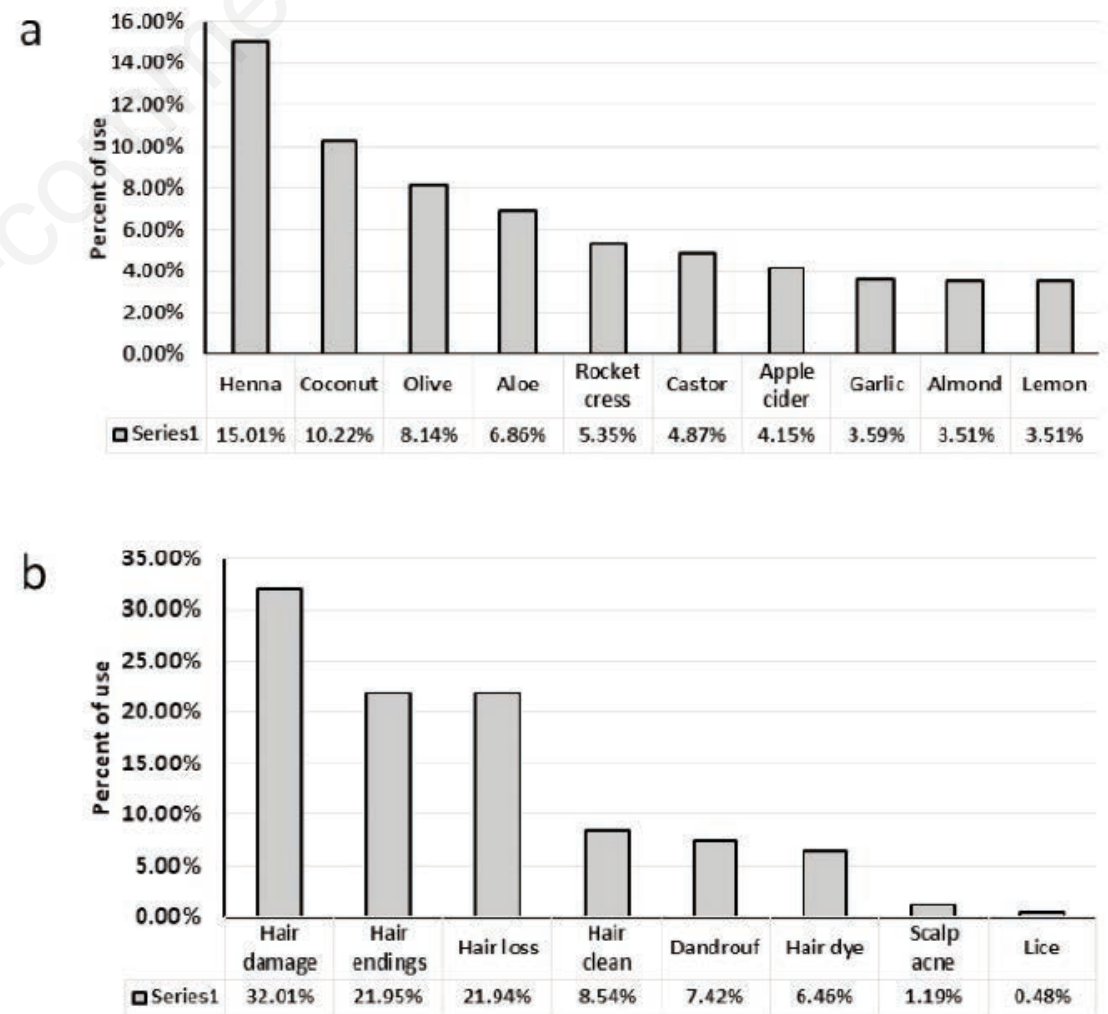

Figure 2. Top ten used herbal medicine in treating hair and scalp disorders (a) and the percentage of different usage of herbal medicine in different hair and scalp disorders (b). 


\section{Herbal medicine used for treatment of hair and scalp}

Participants used 41 medicinal plants as cosmetics and for treating hair and scalp disorders. According to Figure 2, the widely used plants were henna $(15.01 \%)$, coconut $(10.22 \%)$, olive $(8.14 \%)$, aloe $(6.86 \%)$, rocket cress $(5.35 \%)$, castor $(4.87 \%)$, apple cider $(4.15 \%)$, garlic $(3.59 \%)$, almond (3.51\%) and lemon (3.51\%) (Figure 2a). These herbals were used for treating eight major purposes, which are hair damage (32.01\%), hair endings $(21.95 \%)$, hair loss $(21.94 \%)$, hair clean $(8.54 \%)$, dandruff $(7.42 \%)$, hair dye $(6.46 \%)$, scalp acne $(1.19 \%)$ and lice $(0.48 \%)$ (Figure $2 b)$. The percent of use of each herbal plant in hair and scalp were summarized in Table 2. All participants reported that they used the herbal preparations for topical use only. The use of herbal medicine did not differ between participants when they are classified according to their age group or according to their education level. Figure 3a, illustrated the most widely used herbal medicine in treating hair and scalp disorders according to age group, while Figure $3 \mathrm{~b}$ illustrated the most widely used herbal medicine according to education level of participants.

\section{Home remedies used for treatment of hair and scalp}

Eleven home remedies were used in Tabuk as cosmetics or for treating hair and scalp disorders. According to Figure 4, the percentage of use of home remedies were yogurt $(32.42 \%)$, eggs $(26.91 \%)$, honey $(23.85 \%)$, mineral oil $(4.89 \%)$, butter $(3.06 \%)$, fish oil $(2.45 \%)$, milk $(2.45 \%)$, salt $(1.53 \%)$, mayonnaise $(1.22 \%)$, mustard $(0.92 \%)$ and kerosene $(0.31 \%)$ (Figure $4 a)$. These remedies were used for eight major purposes, which are hair damage $(45.57 \%)$, hair endings $(26.91 \%)$, hair loss $(19.88 \%)$, dandruff $(5.19 \%)$, hair clean $(1.22 \%)$, scalp acne $(0.61 \%)$, lice $(0.31 \%)$ and hair dye $(0.31 \%)$ (Figure $4 b)$. The percent of use of each home remedy in hair and scalp were summarized in Table 3. However, all participants in the study revealed that they used the home remedy products only for topical use. Finally, the differences in use of home remedies according to age group or according to education level is summarized in Figure $5 \mathrm{a}$ and $\mathrm{b}$, which revealed no significant differences between subgroups. Figure $5 \mathrm{a}$, illustrated the most widely used home remedies in treating hair and scalp disorders according to age group, while Figure 5b illustrated the most widely used home remedies according to education level of participants. a

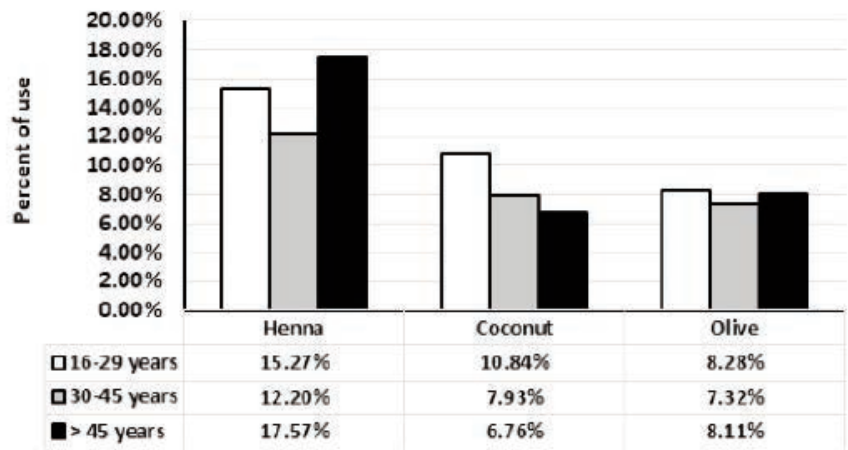

b

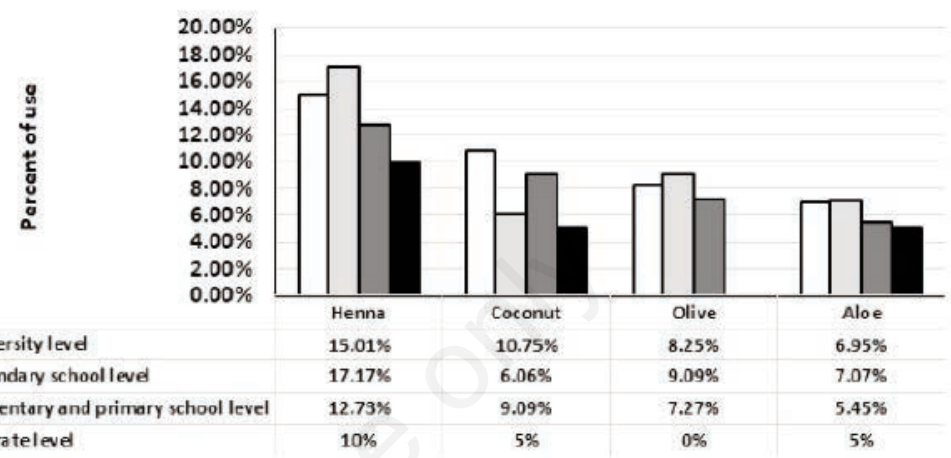

Figure 3. The most widely used herbal medicine in treating hair and scalp disorders according to age group (a) and according to education level of participants (b).

a
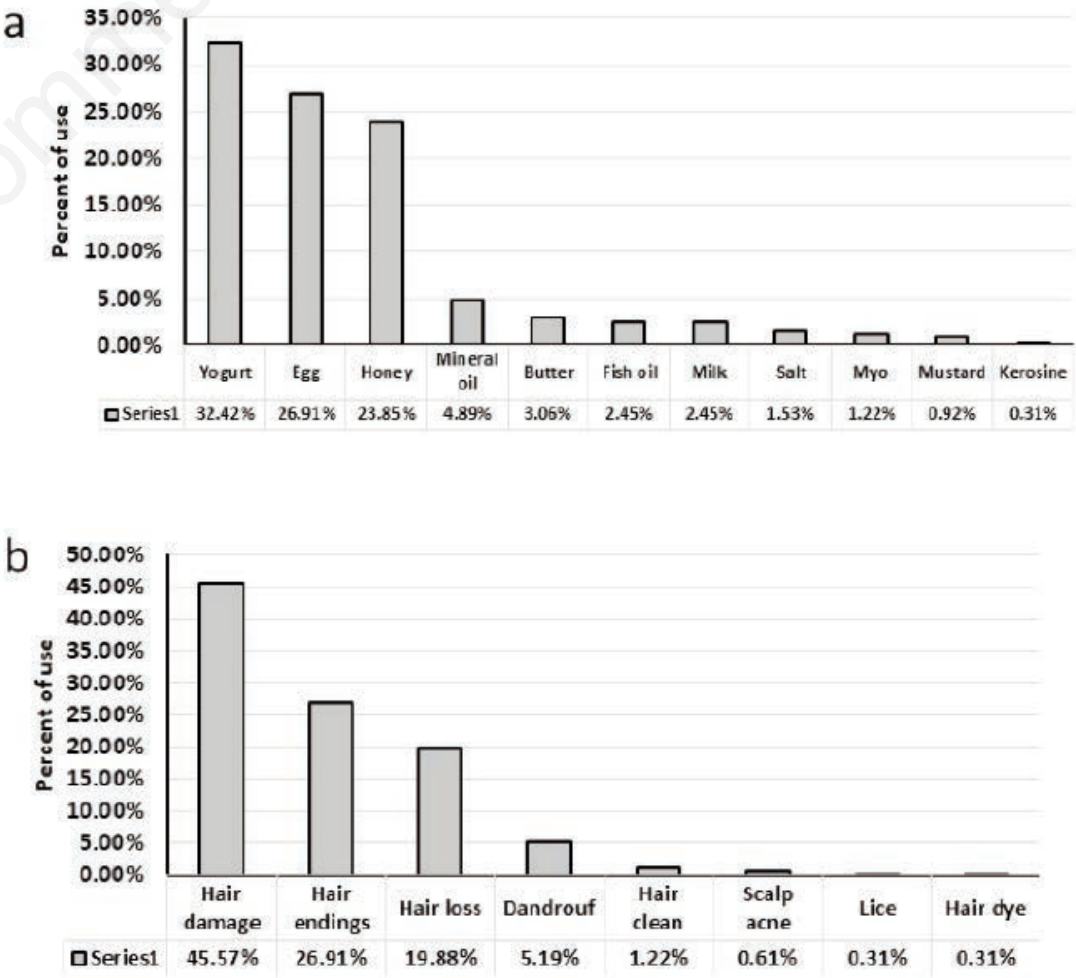

Figure 4. Home remedies used in treating hair and scalp disorders (a) and the percentage of different usage of home remedies in different hair and scalp disorders (b). 


\section{Discussion}

Complementary and alternative medicine describes the diverse medical and health care practice and products, which are not an aspect of conventional medicine. ${ }^{11}$ Although, there is no documented reports about the majority of complementary and alternative therapies, their usage is wide spread worldwide. Medical plants still constitutes a major part of Saudis minds in the field of health care and represented a major source of medicine. ${ }^{12}$ The usage of herbal medicine in Saudi Arabia varies in different studies but all reported high prevalence of use. ${ }^{13-15}$ As a result, we need to perform studies in regard to discover theses therapies and any available clinical trials data about their use. One field which is considered very essential and needs many studies is hair and scalp drugs and cosmetics because they are very important and widely spread. In addition, studying these compounds helps physician and other health providers to improve patients' satisfaction regarding these therapies. Moreover, the results of herbal studies will help in governmental control of herbal medicine, implementation of local regulations for safety and efficacy of herbal products and licensing some herbal therapies. Another major aim of these research studies is to reduce the toxic effects of using herbal and home remedies.

We conducted this study among female subjects only as previous studies revealed that majority of herbal medicine usage was included in female subjects. In addition, female subjects showed better knowledge and positive behavior in regard to safety. ${ }^{11,14,16,17}$ Off note, the use of cosmetic products especially of hair and scalp are more prevalent in female subjects than those of male subjects.

Majority of herbal medicine are available in Saudi Arabia in herbal shops and sold in their crude form. Some new herbal remedies are now available in pharmaceutical dosage forms, which are dispensed through community pharmacies, which is better as these dosages forms contain only registered herbs with emphasis on their purity and safety.

Although, the socio-demographic data reveals that the majority of participants were young in age with high level of education, the major sources of information were represented by social information represented by media, social media, internet, family and friends $(66.44 \%)$ compared with medical books and health practitioners $(29.53 \%)$. This can lead to an important conclusion that many people lack trust of healthcare providers concerning their hair and scalp remedies. They usually prefer getting information from their family, friends and social media. In parallel, physicians' interest in herbal and home remedies is very limited as reported by many studies all over the world. ${ }^{11,18,19}$ A previous study conducted in Riyadh, the capital city of Saudi Arabia, reported that $91.8 \%$ of Saudi physicians did not attend any lecture, training course or workshop about herbal medicine usage and only $20 \%$ of physicians discussed the potential harm and benefits of herbal medicine usage with their patients. ${ }^{11}$ Another study, conducted the southern area of Saudi Arabia, reported $88 \%$ of pharmacists dispense herbal products in their pharmacies and they use these products themselves.

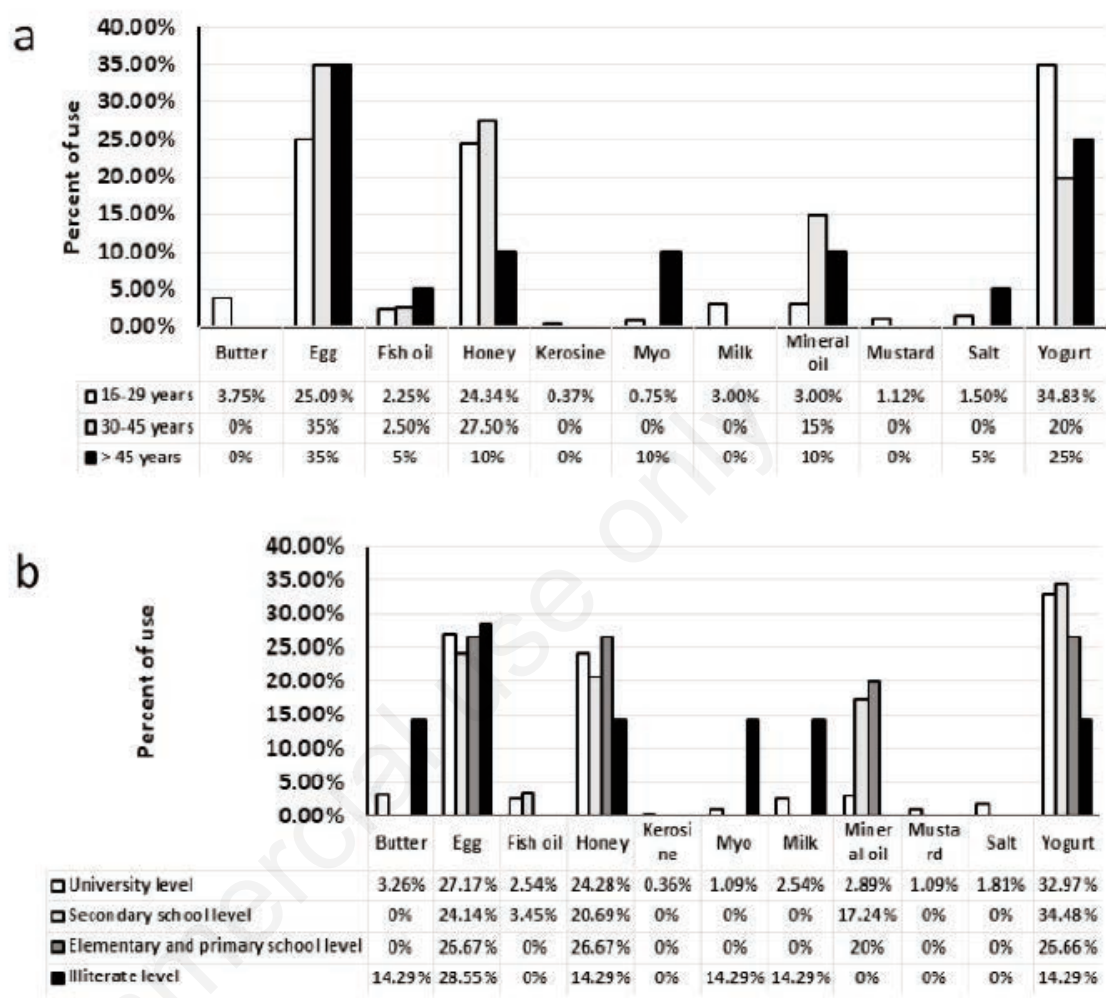

Figure 5. The most widely used home remedies used in treating hair and scalp disorders according to age group (a) and according to education level of participants (b).

Table 1. Socio-demographic characteristics of study population.

\begin{tabular}{lcc}
\hline Variable & N & $(\%)$ \\
Age (Year) & & \\
$16-29$ & 101 & 67.79 \\
$30-45$ & 33 & 22.15 \\
$\quad$ Over than 45 & 15 & 10.06 \\
Education & & \\
$\quad$ University level & 118 & 79.19 \\
Secondary school level & 21 & 14.09 \\
Elementary and primary school level & 8 & 5.37 \\
Illiterate level & 2 & 1.35 \\
\hline Income & & \\
Low income & 103 & 69.13 \\
Medium income & 37 & 24.83 \\
High income & 9 & 6.04 \\
Source of knowledge about natural products & & \\
Medical books & 4 & 2.68 \\
Family and friends & 17 & 11.41 \\
Herbal shops & 6 & 4.03 \\
Physicians and Pharmacist & 40 & 26.85 \\
Internet websites & 19 & 12.75 \\
Media & 22 & 14.77 \\
Social media & 41 & 27.51 \\
$\quad$ & & \\
\hline
\end{tabular}


Table 2. Herbal medicine used for treatment of hair and scalp in North West Saudi Arabia.

\begin{tabular}{|c|c|c|c|c|c|c|c|c|}
\hline & Hair damage & Hair endings & Hair loss & Dandruff & Lice & Scalp acne & Hair clean & Hair dye \\
\hline Almond (n) & 18 & 16 & 8 & 2 & 0 & 0 & 0 & 0 \\
\hline$(\%)$ & 40.91 & 36.36 & 18.18 & 4.55 & 0 & 0 & 0 & 0 \\
\hline Aloe (n) & 39 & 24 & 18 & 3 & 0 & 0 & 2 & 0 \\
\hline$(\%)$ & 45.35 & 27.91 & 20.93 & 3.49 & 0 & 0 & 2.32 & 0 \\
\hline Anise (n) & 0 & 2 & 1 & 0 & 0 & 0 & 0 & 0 \\
\hline (\%) & 0 & 66.67 & 3.33 & 0 & 0 & 0 & 0 & 0 \\
\hline $\begin{array}{l}\text { Apple cider (n) } \\
(\%)\end{array}$ & $\begin{array}{c}6 \\
11.54\end{array}$ & $\begin{array}{c}2 \\
3.85\end{array}$ & $\begin{array}{c}3 \\
5.77\end{array}$ & $\begin{array}{c}24 \\
46.15\end{array}$ & $\begin{array}{c}1 \\
1.92\end{array}$ & $\begin{array}{c}2 \\
3.85\end{array}$ & $\begin{array}{l}13 \\
25\end{array}$ & $\begin{array}{c}1 \\
1.92\end{array}$ \\
\hline Avocado (n) & 15 & 10 & 7 & 0 & 0 & 0 & 1 & 0 \\
\hline$(\%)$ & 45.45 & 30.3 & 21.22 & 0 & 0 & 0 & 3.03 & 0 \\
\hline Banana (n) & 18 & 17 & 4 & 0 & 0 & 0 & 1 & 0 \\
\hline (\%) & 45 & 42.5 & 10 & 0 & 0 & 0 & 2.5 & 0 \\
\hline Bitter (n) & 0 & 1 & 1 & 0 & 0 & 0 & 0 & 0 \\
\hline$(\%)$ & 0 & 50 & 50 & 0 & 0 & 0 & 0 & 0 \\
\hline Castor (n) & 25 & 13 & 20 & 1 & 1 & 0 & 1 & 0 \\
\hline$(\%)$ & 40.98 & 21.31 & 32.79 & 1.64 & 1.64 & 0 & 1.64 & 0 \\
\hline Chamomile (n) & 2 & 1 & 0 & 1 & 0 & 0 & 3 & 2 \\
\hline$(\%)$ & 22.22 & 11.11 & 0 & 11.11 & 0 & 0 & 3.34 & 22.22 \\
\hline Chili pepper (n) & 2 & 1 & 1 & 0 & 0 & 0 & 0 & 0 \\
\hline (\%) & 50 & 25 & 25 & 0 & 0 & 0 & 0 & 0 \\
\hline Clove (n) & 4 & 3 & 4 & 3 & 0 & 0 & 5 & 0 \\
\hline$(\%)$ & 21.05 & 15.79 & 21.05 & 15.79 & 0 & 0 & 26.32 & 0 \\
\hline Coconut (n) & 50 & 33 & 38 & 4 & 0 & 0 & 3 & 0 \\
\hline$(\%)$ & 39.06 & 25.78 & 29.69 & 3.13 & 0 & 0 & 2.34 & 0 \\
\hline Cucumber (n) & 1 & 1 & 0 & 1 & 0 & 0 & 0 & 0 \\
\hline$(\%)$ & 3.33 & 3.33 & 0 & 3.34 & 0 & 0 & 0 & 0 \\
\hline Fenugreek (n) & 12 & 8 & 8 & 2 & 0 & 1 & 1 & 0 \\
\hline$(\%)$ & 37.5 & 25 & 25 & 6.25 & 0 & 3.12 & 3.13 & 0 \\
\hline Garlic (n) & 11 & 6 & 23 & 2 & 0 & 2 & 1 & 0 \\
\hline$(\%)$ & 24.44 & 13.33 & 51.12 & 4.44 & 0 & 4.44 & 2.23 & 0 \\
\hline Ginger (n) & 2 & 0 & 1 & 1 & 0 & 0 & 1 & 0 \\
\hline$(\%)$ & 40 & 0 & 20 & 20 & 0 & 0 & 20 & 0 \\
\hline Henna (n) & 54 & 43 & 33 & 18 & 0 & 0 & 13 & 27 \\
\hline (\%) & 28.72 & 22.87 & 17.55 & 9.57 & 0 & 0 & 6.92 & 14.37 \\
\hline Hibiscus (n) & 3 & 1 & 0 & 1 & 2 & 1 & 7 & 21 \\
\hline (\%) & 8.33 & 2.78 & 0 & 2.78 & 5.56 & 2.78 & 19.44 & 58.33 \\
\hline Jasmine (n) & 0 & 0 & 1 & 0 & 0 & 0 & 0 & 0 \\
\hline$(\%)$ & 0 & 0 & 100 & 0 & 0 & 0 & 0 & 0 \\
\hline Jojoba (n) & 3 & 4 & 3 & 0 & 0 & 1 & 1 & 0 \\
\hline (\%) & 25 & 33.33 & 25 & 0 & 0 & 8.33 & 8.34 & 0 \\
\hline Lavender (n) & 1 & 1 & 2 & 0 & 0 & 0 & 0 & 0 \\
\hline (\%) & 25 & 25 & 50 & 0 & 0 & 0 & 0 & 0 \\
\hline Lemon (n) & 6 & 2 & 3 & 17 & 0 & 1 & 14 & 1 \\
\hline (\%) & 13.64 & 4.55 & 6.82 & 38.64 & 0 & 2.27 & 31.82 & 2.26 \\
\hline Mint (n) & 2 & 1 & 2 & 0 & 0 & 0 & 5 & 2 \\
\hline$(\%)$ & 16.67 & 8.33 & 16.67 & 0 & 0 & 0 & 41.66 & 16.67 \\
\hline Neem (n) & 1 & 0 & 0 & 0 & 0 & 0 & 1 & 0 \\
\hline$(\%)$ & 50 & 0 & 0 & 0 & 0 & 0 & 50 & 0 \\
\hline Nettle (n) & 1 & 0 & 0 & 0 & 0 & 0 & 0 & 0 \\
\hline$(\%)$ & 100 & 0 & 0 & 0 & 0 & 0 & 0 & 0 \\
\hline Nigella (n) & 9 & 3 & 7 & 1 & 0 & 0 & 3 & 0 \\
\hline (\%) & 39.13 & 13.04 & 30.43 & 4.35 & 0 & 0 & 13.05 & 0 \\
\hline Nut meg (n) & 8 & 6 & 4 & 0 & 0 & 1 & 2 & 1 \\
\hline$(\%)$ & 36.36 & 27.27 & 18.18 & 0 & 0 & 4.55 & 9.09 & 4.55 \\
\hline $\begin{array}{l}\text { Olive (n) } \\
(\%)\end{array}$ & $\begin{array}{c}36 \\
35.29\end{array}$ & $\begin{array}{c}32 \\
31.38\end{array}$ & $\begin{array}{c}25 \\
24.51\end{array}$ & $\begin{array}{c}3 \\
2.93\end{array}$ & $\begin{array}{c}1 \\
0.99\end{array}$ & $\begin{array}{c}1 \\
0.99\end{array}$ & $\begin{array}{c}3 \\
2.93\end{array}$ & $\begin{array}{c}1 \\
0.98\end{array}$ \\
\hline
\end{tabular}

Continue to the next page. 
However, only $36 \%$ of these pharmacists provide patients counselling regarding the usage of herbal medicine. ${ }^{15}$ Therefore, the major players in this area is left to untrained practitioners and people with very little knowledge to treat people leading to wide spread of side effects of remedies.

Some of the herbal and home remedies used by people in North West Saudi Arabia are previously approved for their medical and cosmetic use in hair and scalp such as henna, coconut, olive, garlic, honey, butter

Table 2. Continued from previous page.

\section{Hair damage Hair endings Hair loss Dandruff lice Scalp acne Hair clean Hair dye}

\begin{tabular}{|c|c|c|c|c|c|c|c|c|}
\hline Onion (n) & 9 & 8 & 16 & 2 & 0 & 1 & 3 & 2 \\
\hline (\%) & 21.95 & 19.51 & 39.02 & 4.88 & 0 & 2.44 & 7.32 & 4.88 \\
\hline Parsley (n) & 7 & 3 & 3 & 0 & 0 & 0 & 0 & 0 \\
\hline (\%) & 53.84 & 23.08 & 23.08 & 0 & 0 & 0 & 0 & 0 \\
\hline Pomegranate (n) & 0 & 0 & 1 & 1 & 0 & 0 & 3 & 9 \\
\hline$(\%)$ & 0 & 0 & 7.14 & 7.14 & 0 & 0 & 21.43 & 64.29 \\
\hline Quince (n) & 1 & 0 & 0 & 0 & 0 & 0 & 1 & 0 \\
\hline (\%) & 50 & 0 & 0 & 0 & 0 & 0 & 50 & 0 \\
\hline Radish (n) & 0 & 0 & 1 & 0 & 0 & 0 & 0 & 0 \\
\hline (\%) & 0 & 0 & 100 & 0 & 0 & 0 & 0 & 0 \\
\hline Rocket cress (n) & 25 & 16 & 21 & 2 & 1 & 2 & 0 & 0 \\
\hline (\%) & 37.31 & 23.88 & 31.34 & 2.99 & 1.49 & 2.99 & 0 & 0 \\
\hline Rose (n) & 1 & 0 & 0 & 0 & 0 & 0 & 3 & 0 \\
\hline (\%) & 25 & 0 & 0 & 0 & 0 & 0 & 75 & 0 \\
\hline Rosemary (n) & 6 & 3 & 4 & 0 & 0 & 1 & 3 & 2 \\
\hline (\%) & 31.58 & 15.79 & 21.05 & 0 & 0 & 5.26 & 15.79 & 10.53 \\
\hline Sage (n) & 2 & 1 & 3 & 1 & 0 & 0 & 3 & 8 \\
\hline$(\%)$ & 11.11 & 5.56 & 16.67 & 5.56 & 0 & 0 & 16.67 & 44.43 \\
\hline Sesame (n) & 15 & 11 & 6 & 0 & 0 & 1 & 3 & 0 \\
\hline$(\%)$ & 41.67 & 30.5 & 16.67 & 0 & 0 & 2.78 & 8.33 & 0 \\
\hline Shea (n) & 0 & 1 & 0 & 0 & 0 & 0 & 0 & 0 \\
\hline$(\%)$ & 0 & 100 & 0 & 0 & 0 & 0 & 0 & 0 \\
\hline Tea tree (n) & 5 & 0 & 2 & 3 & 0 & 0 & 5 & 3 \\
\hline$(\%)$ & 27.78 & 0 & 11.1 & 16.67 & 0 & 0 & 27.78 & 16.67 \\
\hline Thyme (n) & 1 & 1 & 1 & 0 & 0 & 0 & 2 & 1 \\
\hline$(\%)$ & 16.67 & 16.67 & 16.67 & 0 & 0 & 0 & 33.32 & 16.67 \\
\hline
\end{tabular}

Table 3. Home remedies used for treatment of hair and scalp in North West Saudi Arabia.

\begin{tabular}{|c|c|c|c|c|c|c|c|c|}
\hline & Hair damage & Hair endings & Hair loss & Dandruff & Lice & Scalp acne & Hair clean & Hair dye \\
\hline Butter (n) & 4 & 4 & 1 & 1 & 0 & 0 & 0 & 0 \\
\hline$(\%)$ & 40 & 40 & 10 & 10 & 0 & 0 & 0 & 0 \\
\hline $\operatorname{Egg}(n)$ & 42 & 24 & 16 & 3 & 1 & 0 & 1 & 1 \\
\hline (\%) & 47.72 & 27.27 & 18.18 & 3.41 & 1.14 & 0 & 1.14 & 1.14 \\
\hline Fish oil (n) & 0 & 1 & 4 & 2 & 0 & 0 & 1 & 0 \\
\hline (\%) & 0 & 12.5 & 50 & 25 & 0 & 0 & 12.5 & 0 \\
\hline Honey (n) & 38 & 20 & 18 & 2 & 0 & 0 & 0 & 0 \\
\hline (\%) & 48.72 & 25.64 & 23.08 & 2.56 & 0 & 0 & 0 & 0 \\
\hline Kerosene (n) & 0 & 1 & 0 & 0 & 0 & 0 & 0 & 0 \\
\hline$(\%)$ & 0 & 100 & 0 & 0 & 0 & 0 & 0 & 0 \\
\hline Mayonnaise (n) & 1 & 1 & 1 & 0 & 0 & 0 & 1 & 0 \\
\hline (\%) & 25 & 25 & 25 & 0 & 0 & 0 & 25 & 0 \\
\hline Milk (n) & 4 & 3 & 1 & 0 & 0 & 0 & 0 & 0 \\
\hline$(\%)$ & 50 & 37.5 & 12.5 & 0 & 0 & 0 & 0 & 0 \\
\hline Mineral oil (n) & 10 & 1 & 2 & 2 & 0 & 0 & 1 & 0 \\
\hline (\%) & 62.5 & 6.25 & 12.5 & 12.5 & 0 & 0 & 6.25 & 0 \\
\hline Mustard (n) & 1 & 1 & 0 & 1 & 0 & 0 & 0 & 0 \\
\hline$(\%)$ & 33.33 & 33.33 & 0 & 33.34 & 0 & 0 & 0 & 0 \\
\hline Salt (n) & 2 & 1 & 0 & 1 & 0 & 1 & 0 & 0 \\
\hline$(\%)$ & 40 & 20 & 0 & 20 & 0 & 20 & 0 & 0 \\
\hline Yogurt (n) & 47 & 31 & 22 & 5 & 0 & 1 & 0 & 0 \\
\hline$(\%)$ & 44.34 & 29.25 & 20.75 & 4.72 & 0 & 0.94 & 0 & 0 \\
\hline
\end{tabular}


and fish oil..$^{20-28}$ Many of these studies were performed on animals only or in a very small number of human volunteers giving insufficient information about their efficacy. However, efficacy of the majority of these herbal and home remedies were not studies previously in hair and scalp as fenugreek, chili pepper, cucumber, rocket cress, parsley, onion, milk and eggs. In addition, the use of many of these products was connected with severe side effects or toxic effects of contaminating products associated with them as in henna, castor oil, olive oil, onion and mayonnaise. ${ }^{29-34}$

However, the use of herbal and home remedies are different according to studied area even in the same country according to changes in culture, weather and indigenous plants found in the area. Therefore, this could be an alarm about the widespread use of herbal and home remedies in hair and scalp and their use with nonprofessional providers without any governmental control for their purity and safety.

\section{Conclusions}

Many natural herbal medicine and home remedies are still in use in North West region of Saudi Arabia as cosmetics or treating hair and scalp disorders. There is a great shortage in the medical sources of information about herbal and home remedies used in hair and scalp and the major sources of information were represented by social routes as media, social media, internet, family and friends (66.44\%) compared with medical books and health practitioners $(29.53 \%)$. Finally, many of the used remedies lacks important scientific information about their usage and safety as well as they lack governmental control about their purity.

\section{References}

1. Haslam IS, Smart E. ChemotherapyInduced Hair Loss: The Use of Biomarkers for Predicting Alopecic Severity and Treatment Efficacy. Biomark Insights 2019;14:1177271919842180.

2. Nanashima N, Horie K. Blackcurrant Extract with Phytoestrogen Activity Alleviates Hair Loss in Ovariectomized Rats. Molecules 2019;24:1272.

3. Bater K, Rieder E. Over-the-Counter Hair Loss Treatments: Help or Hype? J Drugs Dermatol 2018;17:1317-21.

4. Li J, Kong XB, Chen XY et al. Protective role of alpha2-macroglobulin against jaw osteoradionecrosis in a pre- clinical rat model. J Oral Pathol Med 2019;48:166-73.

5. Al Aboud AM, Zito PM. Alopecia. In: StatPearls. Treasure Island (FL). 2020.

6. Witte M, Krause L, Zillikens D, Shimanovich I. Black tea dressings - a rapidly effective treatment for facial dermatitis. J Dermatolog Treat 2019;30:785-9.

7. Thomson P, Jones J, Browne M, Leslie SJ. Psychosocial factors that predict why people use complementary and alternative medicine and continue with its use: a population based study. Complement Ther Clin Pract 2014;20: 302-10.

8. Thomson P, Jones J, Browne M, Leslie SJ. Why people seek complementary and alternative medicine before conventional medical treatment: a population based study. Complement Ther Clin Pract 2014;20:339-46.

9. Zaid AN, Jaradat NA, Eid AM et al. Ethnopharmacological survey of home remedies used for treatment of hair and scalp and their methods of preparation in the West Bank-Palestine. BMC Complement Altern Med 2017; 17:355.

10. General Authority for Statistics, Kingdom of Saudi Arabia. Population characteristics surveys in Saudid Arabia, 2017. Available from: https://www.stats.gov.sa/en/5655. Accessed: April 2020.

11. Al-Rowais N, Al-Faris E, Mohammad AG, et al. Traditional healers in Riyadh region: reasons and health problems for seeking their advice. A household survey. J Altern Complement Med 2010;16:199-204.

12. Kamel FO, Magadmi RM, Hagras MM, et al. Knowledge, attitude, and beliefs toward traditional herbal medicine use among diabetics in Jeddah Saudi Arabia. Complement Ther Clin Pract 2017;29:207-12.

13. Elolemy AT, Albedah AM. Public knowledge, attitude and practice of complementary and alternative medicine in riyadh region, saudi arabia. Oman Med J 2012;27:20-6.

14. Allam S, Moharam M, Alarfaj G. Assessing Patients' Preference for Integrating Herbal Medicine Within Primary Care Services in Saudi Arabia. J Evid Based Complementary Altern Med 2014;19:205-10.

15. Alsayari A, Almghaslah D, Khaled A, et al. Community Pharmacists' Knowledge, Attitudes, and Practice of Herbal Medicines in Asir Region, Kingdom of Saudi Arabia. Evid Based Complement Alternat Med 2018;2018:1568139.
16. Allen R, Cushman LF, Morris S, et al. Use of complementary and alternative medicine among Dominican emergency department patients. Am J Emerg Med 2000;18:51-4.

17. Ben-Arye E, Karkabi S, Shapira C, et al. Complementary medicine in the primary care setting: Results of a survey of gender and cultural patterns in Israel. Gend Med 2009;6:384-97.

18. Ismail IA, Chan SC. Knowledge and practice of complementary medicine amongst public primary care clinic doctors in Kinta district, Perak. Med J Malaysia 2004;59:4-10.

19. Ozcakir A, Sadikoglu G, Bayram N, et al. Turkish general practitioners and complementary/alternative medicine. J Altern Complement Med 2007;13: 1007-10.

20. Chowdhury AR, Maddy AJ, Egger AN. Henna as a Hair Dye: A Current Fashion Trend with Ancient Roots. Dermatol 2019;235:442-4.

21. Wallace TC. Health Effects of Coconut Oil-A Narrative Review of Current Evidence. J Am Coll Nutr 2019;38:97107.

22. Radenahmad N, Saleh F, Sayoh I, et al. Young coconut juice can accelerate the healing process of cutaneous wounds. BMC Complement Altern Med 2012;12:252.

23. Bielfeldt S, Blaak J, Staib P, et al. Observer-blind randomized controlled study of a cosmetic blend of safflower, olive and other plant oils in the improvement of scar and striae appearance. Int J Cosmet Sci 2018;40:81-6.

24. Wu X, Li X, Song Y, et al. Allicin protects auditory hair cells and spiral ganglion neurons from cisplatin - Induced apoptosis. Neuropharmacol 2017;116: 429-40.

25. Yeh JE, Hartman RI, Xu J et al. Resolution of folliculitis decalvans with medical honey. Dermatol Online J 2019;25:13030.

26. Witman CE, Downs BW. Topical Honey for Scalp Defects: An Alternative to Surgical Scalp Reconstruction. Plast Reconstr Surg Glob Open 2015;3:e393.

27. Fregonesi A, Scanavez C, Santos L, et al. Brazilian oils and butters: the effect of different fatty acid chain composition on human hair physiochemical properties. J Cosmet Sci 2009;60:273-80.

28. Kang JI, Yoon HS, Kim SM, et al. Mackerel-Derived Fermented Fish Oil Promotes Hair Growth by AnagenStimulating Pathways. Int J Mol Sci 2018;19:2770.

29. Ormerod E, Hughes TM, Stone N. 
Allergic contact dermatitis caused by resorcinol following a temporary black henna tattoo. Contact Dermatitis 2017;77:187-8.

30. Ozbek N, Akman S. Determination of lead, cadmium and nickel in hennas and other hair dyes sold in Turkey. Regul Toxicol Pharmacol 2016;79:49-53.
31. Maduri VR, Vedachalam A, Kiruthika S. "Castor Oil" - The Culprit of Acute Hair Felting. Int J Trichol 2017;9:116-8.

32. Emami N, Daniel SJ. Ototoxicity of olive oil in a chinchilla animal model. Laryngoscope 2013;123:2009-12.

33. Gavazzoni-Dias MF, Rochael M, Vilar E, et al. Eczema-Like Psoriasiform Skin
Reaction due to Brazilian Keratin Treatment. Skin Appendage Disord 2016;1:156-62.

34. Koch E, Clark JM, Cohen B, et al. Management of Head Louse Infestations in the United States-A Literature Review. Pediatr Dermatol 2016;33:466-72. 